are produced and these on fusion now melt to a clear liquid without showing any presence of needles. But if the crystallin plates are allowed to stand at the ordinary temperature for about twelve hours, they are largely converted into the hair like needles as may be shown by a repetition of the phenomena of fusion noted in the first instance.

It would seem, then, that ethyl gallate probably presents two crystallin phases, one the hair like needles, stable at ordinary temperatures, the other, the flat plates stable, if stable at all, at more elevated temperatures, and that further the turbid condition of the fused ester is apparenty due to the presence of masses of unfused needles.

These suggestions are advanced tentatively as the phenomena in question have as yet been only incompletely studied. The investigation, however, is being continued particularly to determin with certainty whether or not the case is actually one of crystallin dimorphism and, if so, to learn the habits of the two crystallin forms and the exact conditions under which one crystallin phase passes into the other.

The peculiar behavior of ethyl gallate on fusion, however interpreted, ${ }^{1}$ serves not only to explain the divergence in melting points given for this substance in the literature, but. also probably explains, in part at least, the mistake of Manning ${ }^{2}$ who, assuming that ethyl gallate melted at I $4 \mathrm{I}^{\circ}$, concluded that the substance melting or changing at $157^{\circ}$ must be another substance.

Berkeley, Cal., Aptil 30, 1912.

\title{
A STUDY OF THE DERIVATIVES OF PHENYL AND ETHYL CYANOACETIC ETHER.
}

By HaRky F, HadLEY.

Received May 10, 1912.

Phenyl- and ethylcyanoacetic acid contain a socalled asymmetric carbon atom. It was the purpose of these experiments to get a separation of each of these acids into the two enantiomorphic modifications.

Some of the salts of phenylcyanoacetic acid were prepared but they decomposed so easily that nothing could be done with them.

Two methods were used in attempting to separate monoethylcyanoacetic acid into its two modifications. First: Salts of this acid were crystallized

${ }^{1}$ It is to be noted that the ethyl gallate prepared by Etti and melting at $14 \mathrm{I}^{\circ}$ was obtained from gallic acid derived from the socalled kinvin. A further study of gallic acid from this source to determin whether or not it is really idenical with ordinary gallic acid seems desirable.

2 In a letter just received from Prof. W. Lash Miller (under whom Mr. Manning carried out his work) in response to a request for a specimen of the so-called ethyl tannate, Prof. Miller likewise states that he has repeated Manning's work and has been able to get only ethyl gallate, instead of ethyl tannate. 
from solution but these salts, excluding the silver salt, were very soluble in water and the crystals were not regular. It was not possible to separate the acid in this manner. Second: The acid was combined with an optically active alkaloid, and an attempt was made to separate the salt by fractional crystallization. This method did not prove successful for the solvents used. However this does not mean that two enantiomorphic modifications do not exist. Possibly with the use of different solvents the two forms might be obtained.

The experiments described in this paper were carried out at the suggestion and under the direction of Prof. J. C. Hessler.

\section{Experimental.}

\section{Derivatives of Phenylcyanoacetic Ether.}

(a) Preparation of the Metallic Salts of Phenylcyanoacetic Acid.Phenylcyanoacetic acid was prepared as directed by Hessler. ${ }^{1}$ About I gram of the açid was treated with $9 \mathrm{cc}$. of water and ammonia was added in slight excess. The solution was then filtered. The excess of ammonia was removed in vacuo over sulfuric acid. To about I cc. of this ammonium salt, a few drops of saturated solutions of each of the following salts were added: $\mathrm{BaCl}_{2}, \mathrm{CuSO}_{4}, \mathrm{~Pb}\left(\mathrm{NO}_{3}\right)_{2}, \mathrm{SnCl}_{2}, \mathrm{KCl}, \mathrm{HgCl}_{2}$, $\mathrm{SrCl}_{2}, \mathrm{CdSO}_{4}$ and $\mathrm{CaCl}_{2}$. The lead salt formed a white precipitate. The copper salt commenced to decompose almost immediately with the evolution of carbon dioxide. The strontium salt gave a slightly turbid solution. All the other salts were soluble. The ammonium salt decomposed on standing with the formation of ammonium carbonate.

(b) Preparation of the Cadmium and Lead Salts of Phenylcyanoacetic Acid.-One gram of phenylcyanoacetic acid was dissolved in water. An excess of cadmium carbonate was added and the mixture left standing 24 hours. The solution was then filtered and the filtrate was evaporated in vacuo over sulfuric acid. When the water had evaporated, the salt formed into white lumps, which possessed a slight odor of the free acid. It was soluble in absolute alcohol and it could not be precipitated with either ether or ligroin. In water at $100^{\circ}$ the salt decomposed. An analysis of the salt by ignition gave the following result:

Calculated for $\left(\mathrm{C}_{9} \mathrm{H}_{6} \mathrm{NO}_{2}\right)_{2} \mathrm{Cd} .3 \mathrm{H}_{2} \mathrm{O}$ : Cd, 23.10; found: 23.02, 23.14.

One gram of phenylcyanoacetic acid was treated with $\mathrm{I} .28$ grams (I molecule) of lead nitrate in water solution. A few cubic centimeters of alcohol were added to keep the materials in solution. Then the calculated amount of half normal sodium hydroxide was added. After a short time a very light yellow, gummy precipitate formed. The solution was then filtered off and the precipitate dried between filter papers. It was then ground in a mortar with water. When the salt was dried it was a slightly

'Am. Chem. J., 32, 127 (1904). 
colored powder. An analysis of the salt, by ignition, gave the following result:

Calculated for $\left(\mathrm{C}_{8} \mathrm{H}_{6} \mathrm{NO}_{2}\right)(\mathrm{PbOH}): \mathrm{Pb}, 53.9 \mathrm{I}$; found: $55.58,55.46$.

(c) Action of Some of the Alkaloid Bases with Phenylcyanoacetic Acid.Phenylcyanoacetic acid was dissolved in dilute alcohol. To part of this solution small amounts of quinoline and pyridine were added. Apparently no reaction took place.

One and seven-tenths grams of phenylcyanoacetic acid were dissolved in about to cc. of absolute alcohol. To this was added 3.53 grams of strychnine. The mixture was shaken about for some time but complete reaction did not take place. Twenty cc. of water were added. On standing one hour carbon dioxide was evolved. No attempt was made to obtain the pure salt.

\section{Derivatives of Ethylcyanoacetic Ether.}

(a) Preparation of Crude Ethylcyanoacetic Ether. ${ }^{1-}$-Fifty grams of ethylcyanoacetic ether were treated with Ioo cc. of absolute alcohol and to this was added an alcoholic solution of 10.2 grams of sodium. 64.24 grams of sodium were then added. With constant shaking the temperature of the solution rose to the boiling point of alcohol within I5-20 minutes. The flask was attached to a reflux condenser and heated slightly until the solution reacted neutral to litmus. After the removal of the excess of alcohol and ethyl bromide, by distillation, water was added and the separated oil was extracted with ether. The dried ether solution gave on distillation an almost colorless liquid boiling at 104-108 at $2 \mathrm{I} \mathrm{mm}$. The highest yield obtained was 52 grams.

(b) Preparation and Properties of the Metallic Salts of Monoethylcyanoacetic Acid.-Monoethylcyanoacetic acid was prepared as directed by Hessler. ${ }^{2}$ In no case was it possible to distil the acid without decomposition. Possibly a sufficiently low pressure could not be secured. One and fifty-two hundredths grams of the acid were dissolved in I 3 cc. of water. The solution was then neutralized with dilute ammonia and filtered. To I cc. of the ammonium salt thus prepared were added 6 drops of saturated solutions of each of the following salts: $\mathrm{Pb}\left(\mathrm{NO}_{3}\right)_{2}$, $\mathrm{CuSO}_{4}, \mathrm{CdSO}_{4}, \mathrm{ZnCl}, \mathrm{BaCl}_{2}, \mathrm{CaCl}_{2}, \mathrm{SrCl}_{2}, \mathrm{NaCl}, \mathrm{KCl}$. No salt gave a precipitate. These solutions were placed in a desiccator over sulfuric acid. The salts had crystallized at the end of three weeks, but nothing could be done with them.

About I cc. of monoethylcyanoacetic acid was dissolved in four parts of water and solid cadmium carbonate was added to this in excess. The mixture was heated over the water bath until the reaction was complete.

${ }^{2}$ Am. Chem. J., 22, I69 (1899).

${ }^{2}$ Ibid., 22, 173 (1899). 
The excess of cadmium carbonate was filtered off and the solution allowed to evaporate in a desiccator over sulfuric acid. The salt thus prepared would not crystallize.

The lead salt of monoethylcyanoacetic acid was prepared by the above described method. This salt did not crystallize.

Three grams of monoethylcyanoacetic acid were dissolved in $27 \mathrm{cc}$. of water and treated with an excess of barium carbonate. The reaction was very rapid. After 24 hours the excess of barium carbonate was filtered off and the solution evaporated in vacuo over sulfuric acid. When the salt was almost dry the excess of material, which was sticking to the crystals, was dissolved in ether. The salt was then dried in vacuo and analyzed. This salt contained crystal water but when an attempt was made to determin the amount of water, the salt decomposed.

The analysis of the salt was made by precipitating the barium as sulfate. Calculated for $\mathrm{C}_{10} \mathrm{H}_{12} \mathrm{~N}_{2} \mathrm{O}_{4} \mathrm{Ba} .4 \mathrm{H}_{2} \mathrm{O}$ : Ba, 31.69; found: $3 \mathrm{I} .82,3 \mathrm{I} .34$.

The strontium salt of monoethylcyanoacetic acid was prepared in just the same way as the barium salt. After the water had been evaporated, the crystallin salt was dissolved in absolute alcohol. When more alcohol was added a gelatinous precipitate was formed. The precipitate was collected and placed in a mortar and worked about until it became granular. The alcohol was then filtered off and the strontium ethylcyanoacetate dried in vacuo over sulfuric acid. When dry the salt is a light brown powder. It absorbs moisture when exposed to the air. By precipitating the strontium as strontium sulfate, analysis gave the following result:

Calculated for $\mathrm{C}_{10} \mathrm{H}_{12} \mathrm{~N}_{2} \mathrm{O}_{4} \mathrm{Sr}$ : Sr, 28. 10; found: 30.00, 30.01.

(c) Preparation and Properties of the Alkaloid Salts of Monoethylcyanoacetic Acid.-To ro grams of monoethylcyanoacetic acid in $90 \mathrm{cc}$. of water were added 30 grams of strychnine. The solution was warmed up to dissolve all of the strychnine salt. A slight excess of strychnine was filtered off and the solution left to crystallize. On cooling a mass of crystals formed. These were freed from the excess of the solution and the solution further concentrated. The crystals were then dried between filter paper and in vacuo over sulfuric acid. This process of concentrating the solution was repeated four times. The salt contained crystal water which was given off at II $5-125^{\circ}$. No true melting point could be determined because the salt decomposed at about $167^{\circ}$. The optical activity of the different fractions was determined, but the results seemed to indicate that there had not been a separation.

Some of the recrystallized strychnine salt was dissolved in warm water. The solution was then cooled and a slight excess of sodium 
hydroxide added. The strychnine was filtered on a weighed filter paper, washed with water, dried and weighed.

Calculated for $\mathrm{C}_{26} \mathrm{H}_{28} \mathrm{~N}_{3} \mathrm{O}_{4} \cdot \mathrm{L}^{1} /{ }_{2} \mathrm{H}_{2} \mathrm{O}$ : Strychnine, 70.54 ; found: $70.4 \mathrm{O}$.

When the salt was placed in vacuo over sulfuric acid it lost most of its water of crystallization. It regained the water of crystallization when left standing in the air.

0.9260 gram of the salt lost 0.0362 gram of water.

Calculated for $\mathrm{C}_{20} \mathrm{H}_{20} \mathrm{~N}_{3} \mathrm{O}_{4}, 1{ }^{1} / 2 \mathrm{HO}: \mathrm{H}_{2} \mathrm{O}, 4.20$; found: $3.9 \mathrm{I}$.

The same method of preparation and crystallization was followed in the preparation of the brucine salt of monoethylcyanoacetic acid as was followed in the preparation and crystallization of the strychnine salt. The brucine salt crystallized more slowly. The salt decomposed when the water of crystallization was given off. The different fractions of the salt showed varying optical activity, but when the free acid was obtained from the different fractions, it did not affect polarized light. Alcohol was not used as a solvent.

(d) Preparation of the Aniline Salt of Monoethylcyanoacetic Acid.-One and one-half grams of monoethylcyanoacetic acid were added to 3 grams of aniline. Heat was evolved. The mixture was heated on the water bath for 2 hours and left to crystallize. At the end of 24 hours the crystals were washed three times with small amounts of ether and dried. Their melting point was $57^{\circ}$. This salt was very soluble in ether and it could not be recrystallized from any other solvent tried. On standing the salt decomposed.

(e) Preparation of Monoethylcyanoacetanilide.-Five grams of monoethylcyanoacetic ether and 7.6 grams (2 molecules) of aniline were placed in a sealed tube and heated at $180^{\circ}$ for 6 hours. On cooling the unchanged aniline and ether were distilled off at reduced pressure. At an outside temperature of $180^{\circ}$ about 6 grams of a dark material remained in the flask. When cool the crystalline material was washed with ether several times, dried and recrystallized from hot water. Analysis gave the following result:

$$
\begin{array}{ll}
\text { Calculated for } \mathrm{C}_{11} \mathrm{H}_{12} \mathrm{~N}_{2} \mathrm{O}: & \text { C, } 70.67 ; \mathrm{H}, 6.43 . \\
\text { Found: } & \text { C, } 70.22 ; \mathrm{H}, 6.96 .
\end{array}
$$

(f) Preparation of Diethylcyanoacetanilide and Diethylcyanoacet-ptoluidide.-Fifteen grams of diethylcyanoacetic ether and 18 grams of aniline were heated to boiling for Io hours. On cooling crystals formed. The yield was small for the amount of material used. The crystals were washed with ether and dried. The salt recrystallized from alcohol in the form of long, light, needle shaped crystals. Melting point 217-218 ${ }^{\circ}$. An analysis gave the following result:

$$
\begin{array}{ll}
\text { Calculated for } \mathrm{C}_{13} \mathrm{H}_{16} \mathrm{~N}_{2} \mathrm{O}: & \mathrm{C}, 72.15 ; \\
\text { Found: } & \text { C, } 71.07,72.50 ; \mathrm{H}, 6.46 .6 .95
\end{array}
$$


Diethylcyanoaceto-p-toluidide was prepared in the same manner as diethylcyanoacetanilide. Analysis of the salt gave the following result:

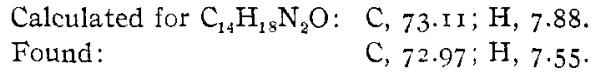

James Militiken Lniversity, Decatur, Ill.,

June, 1911.

[CONTRIBITION FROM THE NUtrtTION LABORATORY OF THE CARNEGIE INSTITUTION OF WASHINGTON, BOSTON, MASSACHUSETTS.]

\section{A CRITICAL STUDY OF SUGAR ANALYSIS BY COPPER REDUCTION METHODS.}

By Amos W. Peters.

Received May 7, 1912:

\section{Introduction.}

The present examination of the processes for the determination of sugar by copper reduction methods had its origin in the needs of this laboratory for numerous daily estimations of sugar in urin. In consequence of the dual requirement of rapidity and accuracy none of the methods examined was found so highly satisfactory as to be adopted without modification. The object of the present work was not to devise a new method of sugar analysis but no less effort was finally required to adapt known procedures to both accuracy and speed and particularly to provide the controls that would guarantee the results obtained. The chief end accomplished, it is hoped, has been the rational selection and the detailed quantitative standardization of the conditions so that exact results can be obtained with rapidity and reliability and with practical freedom from the subjective factor.

The considerations and criticism resulting from an experimental examination of some current methods may be reviewed as follows. A first principle for the selection of a method that is to be rapid is that only volumetric methods can come into consideration. Therefore there remains on this point only the question of the relative accuracy of gravimetric and volumetric estimations of sugar.

Different investigators, $e$. g., Munson and Walker. ${ }^{1}$ pp. $667-668$, and Pfliger ${ }^{2} \mathrm{pp} .47 \mathrm{O}-47 \mathrm{r}$, have shown that the weight of the asbestos filtering apparatus used in the gravimetric method is not constant on account of solution of asbestos and self-reduction of reagents and requires a correction when this can be determined.. Others ${ }^{3}$ working on urin or other

${ }^{1}$ Munson, L. S., and Walker, P. H., "The Unification of Reducing Sugar Methods," THIS JOURNAL, 28,663-683 (1906).

2 Pflüger, E.., Arch. ges. Physiol, 69, 399-47 I (1898).

${ }^{3}$ Neubauer-Huppert, fnal. des Marns, 1 i Aufl, Wiesbaden, rgio, pp. 4ri-12; also Pfii er, Loc, cit. 